\title{
Optimum Electrical Machine Selection for Spacecraft Electro-Mechanical Battery
}

\author{
B. Abdi $^{1}$ J. Milimonfared ${ }^{2}$ J. S. Moghani ${ }^{2}$ \\ 1- Islamic Azad University- Damavand Branch, Tehran, Iran \\ 2- Elec. Eng. Dep., Amirkabir University of technology, Tehran, Iran.
}

\begin{abstract}
Electro-Mechanical Batteries have important advantages comparing chemical batteries and using them is popularized specially in Low Earth Orbit satellites recently. Different type of Permanent Magnet machines are used in these systems as Motor/Generator. Simplified parametric design method is given for synchronous permanent magnet and brushless DC in this paper and finite element based simulations are used to confirm design presses. Finally proper machine is selected based on important parameters in spacecraft.
\end{abstract}

Index Terms - Flywheel, Electromechanical, battery, energy storage, PM, BLDC, design, aerospace.

\section{INTRODUCTION}

Flyw lywheel energy storage or Electro Mechanical Battery (EMB) structuralized by Maryland University [1] and NASA [2] in 1970 decade and using them is popularized specially in Low Earth Orbit (LEO) satellites recently. LEO satellites usually include nano and micro one witch swing around the earth by period of some minutes to a few hours. Against development of chemical battery technology the most critical part of these satellites are their batteries. They have limited life because of fast charge/discharge rate [3].

The advantage of EMB presented in [1 6] that unlimited charge/discharge cycle as well as satellite life, more efficiency, energy density, discharge depths thermal independency and using them in altitude control of satellite can be mentioned. Design rules and flywheel optimization for lower stress and weight done in [4] and design and construction of a EMB of satellite application given in [5].

The most important part of EMB's is Electrical machine used for energy conversion. External rotor Permanent Magnet (PM) machines are used in these systems because of more torque to weight ratio and lower rotor dissipation. Brushless DC(BLDC) machines can produce $15 \%$ more torque than PM machine by the same mass and volume[6] and recommended by NASA for space applications[7] in the other hand PM machines used for some applications like as [8].

In this paper optimal machine for use in spacecraft EMB's will be selected. The steps for this aim are simplified analytical design of each electrical machine. In previous works like as [9] some analytical model presented but they are too complex for design process.

Proper material and structure selection of machine for space applications is presented in section II and simplified design is

e-mail: babakabdi@ieee.org given in III. In the forth section Finite Element Method (FEM) simulation with Ansoft Maxwell-2D software confirm the analytical design and suitable machin will be selected and section $\mathrm{V}$ is conclusion of the paper.

\section{MATERIAL AND CONSTRUCTION SELECTION}

\section{A. Material selection}

Motor/Generator used in spacecraft EMB is a variable and high speed small machine with some limitations as thermal, heat transfer, volume and mass. Rotor or flywheel is floated by magnetic bearings in EMB's and rotor dissipations excrete by radiation. Therefore the magnets installed on rotor surface experience high temperature and its variations. Then the adequate PM for this application is samarium-cobalt (Sm-Co).

Ferromagnetic material used in stator and rotor back iron is chosen according their losses at working point and saturation level. Among ferromagnetic materials Iron-cobalt and amorphous iron are candidate. Amorphous iron is chosen because of its lower losses.

Kapton is appropriate for electrical insulation and Litz wires are used for skin effect reduction $[5,10]$.

\section{B. Proper structure}

kinetic energy stored in a flywheel $\left(\frac{1}{2} I \omega^{2}\right)$ is related by inertia and square of angular velocity and inertia $\left(\frac{1}{2} m r^{2}\right)$ is related by mass and square of flywheel radius then angular velocity and radius have to be as large as possible for volume and mass optimization. Finally proper structure for spacecraft EMB is a hollow cylinder with centered external rotor electrical machine as shown in Fig. 1. The manner of PM installation on rotor is another important parameter. Surface mounted permanent magnet machines are proper because of higher energy density and lower harmonic production [11]. The final important parameter is the pole number of machine. 2 or 4 pole machines are used for high speed applications to minimize the core losses but torque creation of 4 pole machine is about five times of 2 pole one $[5,12,13]$ and proper pole number for spacecraft EMB is 4.

\section{Simplified PARAMETRIC MACHINE DeSign}

Parametric design will be done according fig.1. Permanent magnet machine design for EMB application consist flowing steps generally[14]:

- Determination of flux density functions in air gap.

- Calculation of current and turn-number according required torque and output voltage. 
- Calculation of necessary Iron area according working point remains below the flux density saturation point.

- Calculation of necessary slot space according copper and insulators area and filling factor.

-Determination of outer radius according necessary inertia and kinetic energy.

- Determination of losses for optimization.

After solving Poisson's equation for the PM magnetic field [15] in the polar coordinate system, the final solution for the radial air gap field is given by:

$$
\begin{aligned}
& B_{\text {air } 1}(r, \theta)=\sum_{n=1}^{\infty} \frac{M_{n}}{\mu_{m}} \frac{n p}{n p^{2}-1} R_{5}^{-(n p-1)} \times \\
& \left\{\begin{array}{c}
\frac{(n p-1) R_{5}^{2 n p}+2 R_{6}^{(n p+1)} R_{5}^{(n p-1)}-(n p+1) R_{6}^{2 n p}}{\frac{\mu_{m}+1}{\mu_{m}}\left[R_{4}^{2 n p}-R_{6}^{2 n p}\right]-\frac{\mu_{m}-1}{\mu_{m}}\left[R_{5}^{2 n p}-R_{4}^{2 n p}\left(\frac{R_{6}}{R_{5}}\right)^{2 n p}\right]} \\
\times\left[r^{(n p-1)}+R_{4}^{2 n p} r^{-(n p+1)}\right] \cos (n p \theta)
\end{array}\right.
\end{aligned}
$$

Where $M_{\mathrm{n}}$ is magnetic vector and for radially magnetized PM:

$$
M_{n}=2 B_{r} \alpha_{p} \frac{\sin \left(\frac{n \pi \alpha_{p}}{2}\right)}{\left(\frac{n \pi \alpha_{p}}{2}\right)}
$$

And $R_{4}$ is stator outer diameter, $R_{5}$ and $R_{6}$ are inner and outer radius of PM respectively, $\mathrm{p}$ is the number of pole pair and $\alpha_{p}$, $\mu_{m}, B_{r}$ are PM arc to pole pitch ratio, magnet remnant and magnet permeability respectively. Equation (1) is a complex series and deeply depend on PM and air gap width and couldn't be convert to a simple equation.

Using equation (1) in parametric design cause very complex design equations and their solving need much time as well as not appropriate for optimization. By assuming $\mu_{m}=1$, $\mu_{r}=\infty$ where $\mu_{r}$ is Iron permeability, air gap flux can be rewritten as[12]:

$B_{\text {air } 2}=B_{r} \frac{L_{m}}{L_{m}+L_{g}}=B_{r} \frac{R_{6}-R_{5}}{R_{6}-R_{4}}$

Difference between Amount of equations (1) and (3) for $\mathrm{R}_{4}=17 \mathrm{~mm}, \mathrm{R}_{5}=18 \mathrm{~mm}, \mathrm{R}_{6}=20 \mathrm{~mm}, \alpha_{p}=0.66$ is about $5 \%$ and acceptable for a simple design and optimization. Considering independency of $B_{\text {air } 2}$ to radius in equation (3), overall torque and phase induced voltage can be determined as follows:

$T_{p m}=\frac{3}{2} \Psi i$

$T_{B L D C}=2 \Psi i$

$E_{B L D C \text { (phase })}=E_{P M(\text { phase })}=\Psi \omega$

$\Psi=2 \mathrm{pNB}_{\mathrm{p}} \mathrm{K}_{\alpha} \mathrm{ZR}_{4}$

$\mathrm{K}_{\alpha}=\cos \left(\pi \frac{1-\alpha_{\mathrm{p}}}{2}\right)$

Where $\mathrm{N}, \mathrm{Z}, \omega$ are coil turn number, axial length and angular velocity of rotor respectively and $\mathrm{K}_{\alpha}$ is fist harmonic coefficient of magnetic field Fourier series and show the effect of $\alpha_{p}$.

According Fig. 1 air gap reluctance in front of dent and pole is:
$\mathcal{R}_{t}=\frac{N_{t}\left(R_{6}-R_{4}\right)}{\mu_{0} \pi Z\left(R_{6}+R_{4}\right)}$

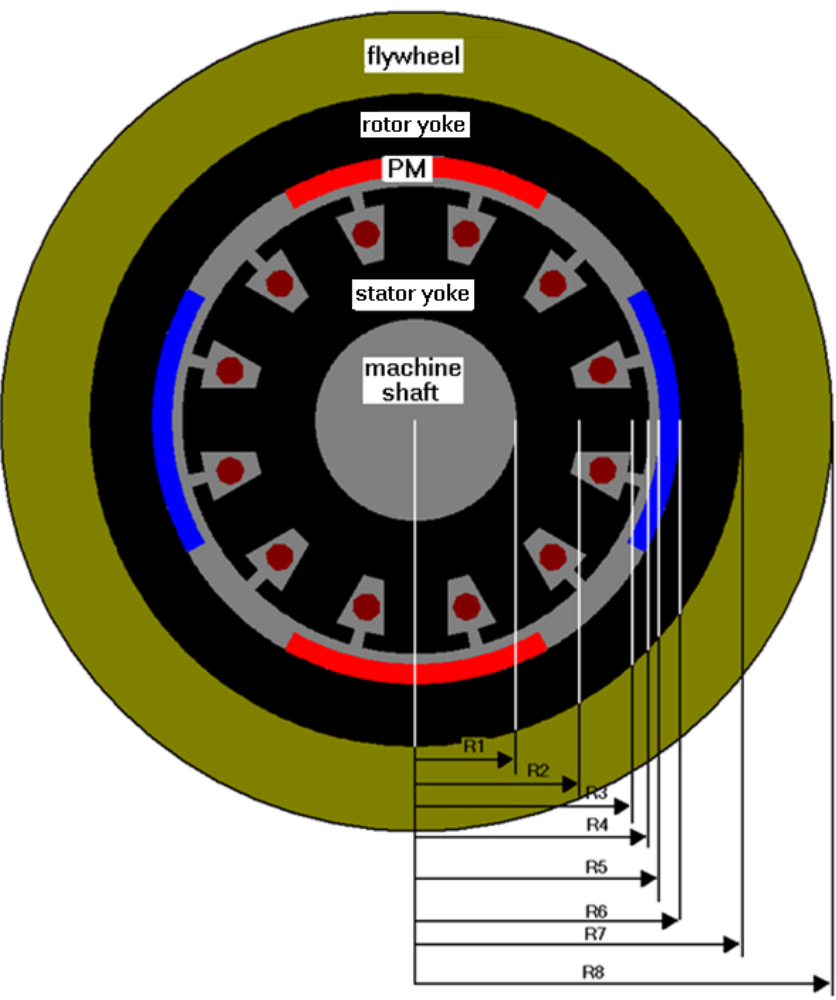

Fig. 1. Electro mechanical Battery under design

$\mathcal{R}_{p}=\mathcal{R}_{t} \frac{2 p}{N_{t}}$

So the produced flux by coil and magnet can be calculated as:

$\varphi_{t(\text { coil })}=\frac{N i}{\mathcal{R}_{t}}$

$\varphi_{t(\text { magnet })}=\frac{B_{r}\left(R_{6}-R_{5}\right)}{\mu_{0} \mathcal{R}_{t}}$

And maximum total flux of each dent determined by:

$\varphi_{t(\text { total })}=a \varphi_{t(\text { coil })}+\varphi_{t \text { (magnet })}$

Where for PM machine $\mathrm{a}=1.5$ and for BLDC machines $\mathrm{a}=2$.

From working point below flux density saturation width of stator and rotor yoke and dent can be calculated as:

$W_{t}=\frac{\varphi_{t(\text { total })}}{Z B_{\max }}$

$W_{y}=\frac{1}{2} \frac{N_{t}}{2 p} W_{t} \alpha_{p}$

Coil current and turn number can be finding according machine torque and induced voltage (eq. 4 to 6 ) then the necessary slot space is:

$A_{c u}=\frac{12 p N i K_{c u}}{N_{t} f f}$

Where $f f, K_{c u}$ are filling factor and necessary cupper area for flow one ampere of current respectively. On the other hand according Fig. 1 available slot space is: 
$A_{s}=\frac{\pi\left(R_{3}^{2}-R_{2}^{2}\right)}{N_{t}}-W_{t}\left(R_{3}-R_{2}\right)$

By equalize necessary and available space:

$A_{s}=A_{c u} \Rightarrow$

$R_{3}^{2}-\frac{N_{t} W_{t}}{\pi} R_{3}+\frac{N_{t} W_{t}}{\pi} R_{2}-R_{2}^{2}-\frac{A_{c u} N_{t}}{\pi}=0$

Where:

$R_{2}=W_{t}+R_{1}$

By solving equation (18) all machine dimension will be find except outer radius of flywheel. The kinetic energy stared on a hallow cylinder define as [4]:

$$
\begin{aligned}
& E=P t=\frac{1}{2} I_{\text {total }}\left(\omega_{2}^{2}-\omega_{1}^{2}\right) \\
& I_{\text {total }}=I_{P M}+I_{F e}+I_{\text {com }} \\
& =\frac{1}{2} Z \pi\left[\rho_{P M}\left(R_{6}^{2}-R_{5}^{2}\right)^{2}+\rho_{F e}\left(R_{7}^{2}-R_{6}^{2}\right)^{2} \rho_{c o m}\right. \\
& \left.+\left(R_{8}^{2}-R_{7}^{2}\right)^{2}\right]
\end{aligned}
$$

Where $\omega_{1}, \omega_{2}$ are lower and higher cylinder speed and $\rho_{P M}, \rho_{F e}, \rho_{\text {com }}$ are weight density of PM, rotor back Iron and flywheel composite. By solving equation (21) all machine dimension are calculated.

Wire length of each phase is:

$l_{\text {phase }}=4 p N\left[(Z+2 e)+\frac{\pi\left(R_{3}+R_{2}\right)}{2 p}\right]$

Where $e$ is axial salient length of coil from stator. The resistance of each phase and total copper loss can be calculated as:

$R_{\text {phase }}=l_{\text {phase }} \rho_{c u}=4 p N\left[(Z+2 e)+\frac{\pi\left(R_{3}+R_{2}\right)}{2 p}\right] \rho_{c u}$

$P_{c u}=3 R_{\text {phase }} i^{2}$

Where $\rho_{c u}$ is special copper resistance. Finally stator mass is determined by:

$m_{F e}=V_{o l} D_{F e}$

$=\left[\pi\left(R_{2}^{2}-R_{1}^{2}\right)+W_{t} N_{t}\left(R_{4}-R_{2}\right)\right] Z D_{F e}$

Where $D_{F e}$ is iron weight density. Iron loss can be defined from factory datasheets. It is noticeable that the flux of rotor back iron is constant and its losses can be ignored.

Design result for given parameters of table (1) are shown in table (2) for both machine.

\section{DESIGN CONFIRMATION AND COMPARISON}

Finite element simulations with ANSOFT Maxwell-2D software have been done for analytical design confirmation.

The result of magnetostatic simulation for two machines are deeply closed together because both machines are designed for same maximum magnetic flux density then Fig. 2 shows magnetic flux density distribution resulted by simulation for both machine and confirms the parametric design.

Parametric magnetostatic simulation is done in $\omega t=\pi / 2$, where phase's currents are $I_{a}=2.4, I_{b}=I_{c}=-1.2$ for PM machine and $I_{a}=I_{b}=2.08, I_{c}=0$ for BLDC machine. In the simulation each pole shifted 7.5 degree[13] and $\alpha_{p}=0.66$ [14] for cogging torque reduction.

Fig. 3 shows produced torque by two machine resulted by FEM simulation.

The maximum obtained torque from FEM simulation are 0.0255 and 0.0248 for PM and BLDC machines respectively. By comparing this value with required value $(0.0239 \mathrm{Nm})$, the TABLE I

GIVEN PARAMETERS FOR MACHINE DESIGN

\begin{tabular}{|c|c|c|c|c|c|c|}
\hline & $\begin{array}{c}\mathrm{R}_{1} \\
(\mathrm{~mm})\end{array}$ & $\begin{array}{c}\mathrm{R}_{2} \\
(\mathrm{~mm})\end{array}$ & $\begin{array}{c}\mathrm{R}_{3} \\
(\mathrm{~mm})\end{array}$ & $\begin{array}{c}\mathrm{R}_{4} \\
(\mathrm{~mm})\end{array}$ & $\begin{array}{c}\mathrm{R}_{5} \\
(\mathrm{~mm})\end{array}$ & $\begin{array}{c}\mathrm{R}_{6} \\
(\mathrm{~mm})\end{array}$ \\
\hline PM & 10 & 16.1 & 21.3 & 22.8 & 23.8 & 25.6 \\
\hline \multirow[t]{2}{*}{ BLDC } & 10 & 15.9 & 20 & 22 & 23 & 25 \\
\hline & $\begin{array}{c}\mathrm{R}_{7} \\
(\mathrm{~mm})\end{array}$ & $\begin{array}{c}\mathrm{R}_{8} \\
(\mathrm{~mm})\end{array}$ & $\mathrm{N}$ & $\mathrm{P}_{\mathrm{cu}}$ & $P_{f e}$ & $\begin{array}{l}\text { Eff. } \\
(\%)\end{array}$ \\
\hline PM & 32.4 & 135.7 & 4.2 & 0.54 & 2.79 & 93.7 \\
\hline \multirow[t]{2}{*}{ BLDC } & 30.5 & 135.3 & 3.7 & 0.48 & 2.6 & 94.2 \\
\hline & $\begin{array}{c}\text { Machine } \\
\text { Mass } \\
(\mathrm{Kg})\end{array}$ & $\begin{array}{c}\text { Overall } \\
\text { Mass } \\
(\mathrm{Kg})\end{array}$ & $\begin{array}{c}\text { Machine } \\
\text { Volume } \\
(\mathrm{cm} 3)\end{array}$ & $\begin{array}{c}\text { Overall } \\
\text { Volume } \\
(\mathrm{cm} 3)\end{array}$ & & \\
\hline PM & 0.55 & 6.24 & 98.9 & 3471 & & \\
\hline BLDC & 0.46 & 6.21 & 87.7 & 3450 & & \\
\hline
\end{tabular}

\begin{tabular}{|c|c|c|c|c|c|}
\hline $\mathrm{P}$ & $\mathrm{t}$ & $\mathrm{N}$ & $\mathrm{E}_{\mathrm{l}-\mathrm{l}}$ & $\mathrm{ff}$ & $\mathrm{B}_{\max }$ \\
\hline $50 \mathrm{Watt}$ & $1800 \mathrm{sec}$. & $20 \mathrm{krpm}$ & $24 \mathrm{~V}$ & 0.6 & $1.4 \mathrm{~T}$ \\
\hline & & & & & \\
\hline $\mathrm{N}_{\mathrm{t}}$ & $\mathrm{N}_{\mathrm{p}}$ & $\mathrm{L}_{\mathrm{g}}$ & $\mathrm{L}_{\mathrm{m}}$ & $\mathrm{Z}$ & $\mathrm{a}_{\mathrm{p}}$ \\
\hline 12 & 4 & $1 \mathrm{~mm}$ & $2 \mathrm{~mm}$ & $30 \mathrm{~mm}$ & 0.66 \\
\hline
\end{tabular}

TABLE II

DESIGN RESULTS FOR COMPARISON

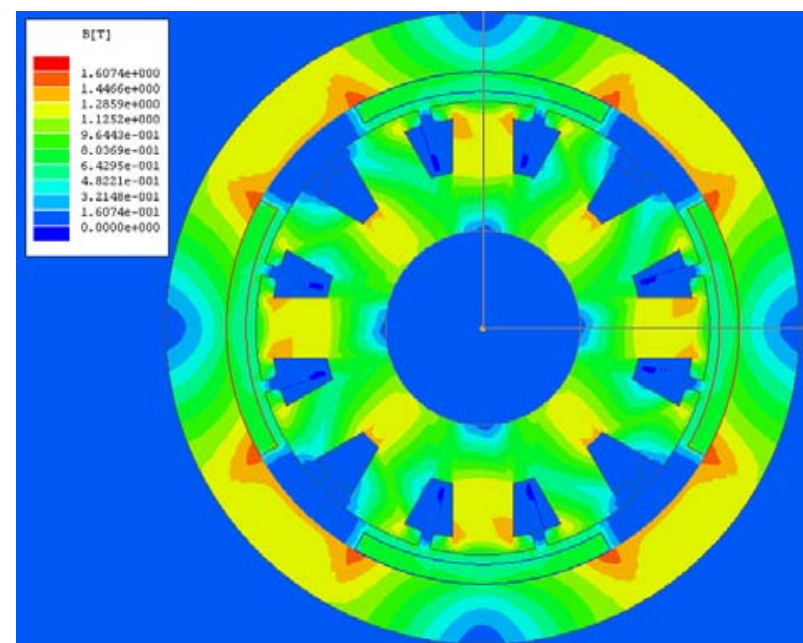

Fig. 2. Magneto static finite element simulation result of machine

errors are $6.7 \%$ and $3.7 \%$ for $\mathrm{PM}$ and BLDC machines respectively that are suitable for design. Referring table I, it can be find that for the same output power and axial length, machine outer radius $\left(\mathrm{R}_{7}\right)$ and volume of $\mathrm{PM}$ machine is $6.2 \%$ and $12.8 \%$ more than BLDC machine respectively. If the center hole of machines is eliminated, these value changes to 
$7.2 \%$ and $15 \%$.

By comparing outer flywheel $\operatorname{radius}\left(\mathrm{R}_{8}\right)$ it can be find that flywheel radius, overall mass and overall volume are equal in both systems. But using BLDC machines have two important disadvantages. Phase current of BLDC machines is triangular and large amount of harmonics are produced during commutation. More filter volume and mass is needed to overcome these harmonics. The second problem is torque ripple generated by phase current replacement. The recent reaserch are given in $[18,19]$ but each method have some disadvantages.

By attention to above discussion it can be summarized that PM machines are more suitable in spacecraft EMB's.

\section{CONCLUSION}

Simplified parametric design of two type of external rotor, permanent magnet machines used in spacecraft elactromachanical batteries presented in this paper. The results of parametric design applied to finite element method simulation. The simulation results show that errors are $6.7 \%$ and $3.7 \%$ for PM and BLDC machines respectively that are suitable for design. By comparing design result for same output power it is found that mass and volume of electrical machine is negligible comparing overall system mass and volume then PM machines is selected for this application because of lower input harmonic and torque ripple generations.

\section{REFERENCES}

[1] J.A. Kirk, P.A. Studer, "Flywheel Energy Storage" Int. J. mech. Sci., VoL 19, pp. 233-245. Pergamon Press 1977.

[2] G.E. Rodriguez, P.A. Studer, D.A. Baer, "Assessment of Flywheel Energy Storage for Spacecraft Power Systems", NASA Technical Memorandum, May 1983.

[3] E. Lee, "A micro HTS renewable energy/attitude control system for micro/nano satellites", IEEE Transaction on Applied Superconductivity, VOL. 13, NO. 2, JUNE 2003.

[4] M. A. Arslan, "Flywheel geometry design for improved energy storage using finite element analysis", ELSEVIER Transaction on material and design, 2007.

[5] W. Wang, "Design of High Speed Flywheel Motor/Generator for Aerospace Applications", PhD Thesis, The Pennsylvania State University, 2003.

[6] L. Parsa, "Performance Improvement of Permanent Magnet AC Motors"' PhD Thesis, Texas A\&M University, 2005.

[7] "Selection of Electric Motor for Aerospace Applications", NASA, Preferred Reliability Practices, Practice No. PD-ED-1229.

[8] B. H. Kenny, P. E. Kascak, R. Jansen, T. Dever, W. Santiago, "Control of a high-speed flywheel system for energy storage in space applications", IEEE Transaction on Industry Applications, VOL. 41, NO. 4, JULY/AUGUST 2005.

[9] S. R. Holm, H. Polinder, J. A. Ferreira, "Analytical Modeling of a Permanent-Magnet Synchronous Machine in a Flywheel", IEEE Transaction on Magnetics, VOL. 43, NO. 5, MAY 2007.

[10] W. Wang, D. Zhong, H. Hofmann, J. Noland, C. E. Bakis, " Design of High-Speed Permanent Magnet Machine for Small Flywheels", 1st International Energy Conversion Engineering Conference, August 2003.

[11] A.S. Nagorny, N.V. Dravid, R.H Jansen, B.H. Kenny, "Design Aspect of a High Speed Permanent Magnet Synchronous Motor/Generator for Flywheel Applications", IEEE Conference, 2005.

[12] M. Popescu, D.M. Ionel, T.J.E. Miller, S.J. Dellinger, M.I. McGilp, "Improved finite element computations of torque in brushless permanent magnet motors", IEE Proc.-Electr. Power Appl., Vol. 152, No. 2, March 2005.

[13] D. M. Ionel, M. Popescu, M. I. McGilp, T. J. E. Miller, S. J. Dellinger, "Assessment of Torque Components in Brushless Permanent-Magnet
Machines Through Numerical Analysis of the Electromagnetic Field", IEEE Transaction on Industry Applications, VOL. 41, NO. 5, SEPTEMBER/OCTOBER 2005.

[14] J. F. Gieras, M. Wing, "Permanent Magnet Motor Technology, Design and Applications", Second edition, Marcel Dekker, 2002.
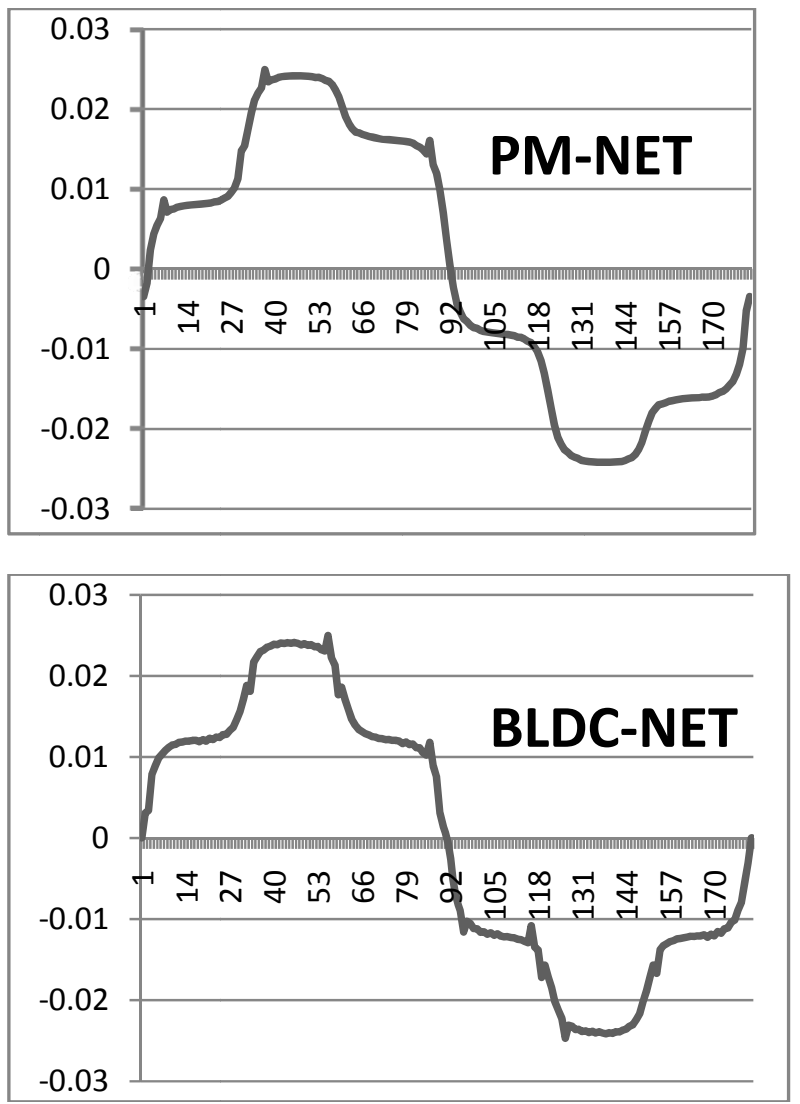

Fig. 3. Magneto static finite element simulation result of two machines

[15] Z. Q. Zhu, D. Howe, "Instantaneous magnetic field distribution in permanent magnet brushless DC motors", IEEE Transactions on Magnetics Volume 29, Issue 1, Jan 1993.

[16] C. Bretón, J. Bartolomé, J. A. Benito, G. Tassinario, I. Flotats, C. W. Lu, and B. J. Chalmers, "Influence of Machine Symmetry on Reduction of cogging Torque in Permanent-Magnet Brushless Motors", IEEE Transaction on Magnetics, VOL. 36, NO. 5, SEPTEMBER 2000.

[17] Z. Q. Zhu, D. Howe, "Influence of Design Parameters on Cogging Torque in Permanent Magnet Machines", IEEE Transaction on Energy Conversion, VOL. 15, NO. 4, DECEMBER 2000.

[18] Y. Liu, Z. Q. Zhu, D. Howe, "Direct Torque Control of Brushless DC Drives With Reduced Torque Ripple", IEEE Transaction on Industry Applications, VOL. 41, NO. 2, MARCH/APRIL 2005.

[19] D. Kim, K. Lee, B. Kwon, "Commutation Torque Ripple Reduction in a Position Sensorless Brushless DC Motor Drive", IEEE Transaction on Power Electronics, VOL. 21, NO. 6, NOVEMBER 2006. 